\title{
CARACTERIZAÇÃO DAS COMUNIDADES VEGETAIS NA RESTINGA DE MARICÁ, RIO DE JANEIRO, SUDESTE DO BRASIL
}

\section{Caracterization of Vegetable Communities in The Maricá Restinga, Rio de Janeiro, Southeast of Brazil}

\author{
Cátia Pereira dos Santos \\ Doutoranda em Dinâmica dos Oceanos e da Terra; Lagemar, UFF \\ catia-ps@hotmail.com \\ Heloisa Helena Gomes Coe \\ Professora Adjunta do Departamento de Geografia da FFP UERJ \\ heloisacoe@yahoo.com
}

Yame Bronze Medina Ramos Mestre em Dinâmica dos Oceanos e da Terra; Lagemar, UFF

yamemedina@hotmail.com

Leandro de Oliveira Furtado de Sousa Professor Adjunto do Departamento de Ciências Vegetais da UFERSA leandro@ufersa.edu.br

André Luiz Carvalho da Silva Professor Adjunto do Departamento de Geografia da FFP UERJ andrelcsilvageouerj@gmail.com

Désirée Guichard Freire Professora Assistente do Departamento de Geografia da FFP da UERJ desireeuerj@gmail.com

Carolina Pereira Silvestre Doutoranda em Dinâmica dos Oceanos e da Terra; Lagemar, UFF cps silvestre@hotmail.com Artigo recebido em 18/10/2016 e aceito para publicação em 15/05/2017

DOI: $10.12957 /$ tamoios.2017.26120

\section{Resumo}

A restinga, vegetação predominante na planície costeira de Maricá no Estado do Rio de Janeiro, vem sendo devastada nas últimas décadas devido à ocupação desordenada que afeta os ecossistemas e altera profundamente a paisagem. Os objetivos desse trabalho estão voltados para a caracterização das comunidades vegetais da restinga na Área de Proteção Ambiental de Maricá e das espécies vegetais dominantes. Estudos dessa natureza ainda são possíveis graças à preservação desta restinga, o que permite um maior conhecimento sobre a biogeografia da região, importante para o desenvolvimento responsável e para um gerenciamento costeiro eficaz. Para isto, foram realizados trabalhos de campo para a caracterização das comunidades vegetais e das principais espécies que as constituem. Foram identificadas as espécies mais representativas de oito comunidades vegetais: halófila-psamófila, duas comunidades scrub, dois brejos herbáceos, slack, floresta seca e vegetação arbustiva nas margens da lagoa.

Palavras-chave: Maricá; restinga; comunidades vegetais; planície costeira.

\begin{abstract}
"Restinga" is the predominant vegetation of the coastal plain of Maricá, Rio de Janeiro, Brazil. In recent decades, this area has been suffering the effects of a process of disorderly occupation, affecting ecosystems and profoundly altering the landscape. Our objective is to characterize the vegetation communities of the Environmental Protection Area of Maricá and their dominant plant species. Studies of this nature enable a better understanding of the dynamics of the region, and contribute to the sustainable development of these areas, through effective measures of integrated coastal management. It was therefore necessary to perform a survey of the species present in each vegetal community. The following vegetation communities and their dominant species were characterized: halophyte-psamophyte, two scrub communities, two herbaceous swamps, slack, dry forest and shrubland vegetation on the shores of the lagoon.
\end{abstract}

Keywords: Maricá; "Restinga"; vegetal communities; coastal plain. 


\section{INTRODUÇÃO}

A Área de Proteção Ambiental (APA) de Maricá, uma Unidade de Conservação estadual criada em 1984, é formada por três componentes: a Ilha Cardosa, a Ponta do Fundão, (ambas recobertas por floresta atlântica) e, ainda, a porção central da planície costeira do município. A estrutura desta planície costeira é composta por um sistema barreira-laguna, constituída por vários micro-ambientes e recoberto por vegetação de restinga, sendo, portanto, um componente do Bioma Mata Atlântica. Tal localidade, denominada no meio acadêmico, popular e institucional como "Restinga de Maricá", é o objeto do nosso estudo (Figura 1).

Esta investigação objetivou caracterizar as comunidades vegetais da restinga da APA de Maricá (Figura 1), as espécies vegetais dominantes em cada uma delas e as variáveis ambientais responsáveis por sua distribuição geográfica Este trecho do litoral, a "Restinga de Maricá", representa uma das poucas áreas desprovidas de construções e, por isso, de grande relevância para a realização de estudos dessa natureza. A vegetação de restinga, assim como fragmentos de Mata Atlântica, ainda estão bem preservados, principalmente quando comparados às áreas adjacentes à APA de Maricá.

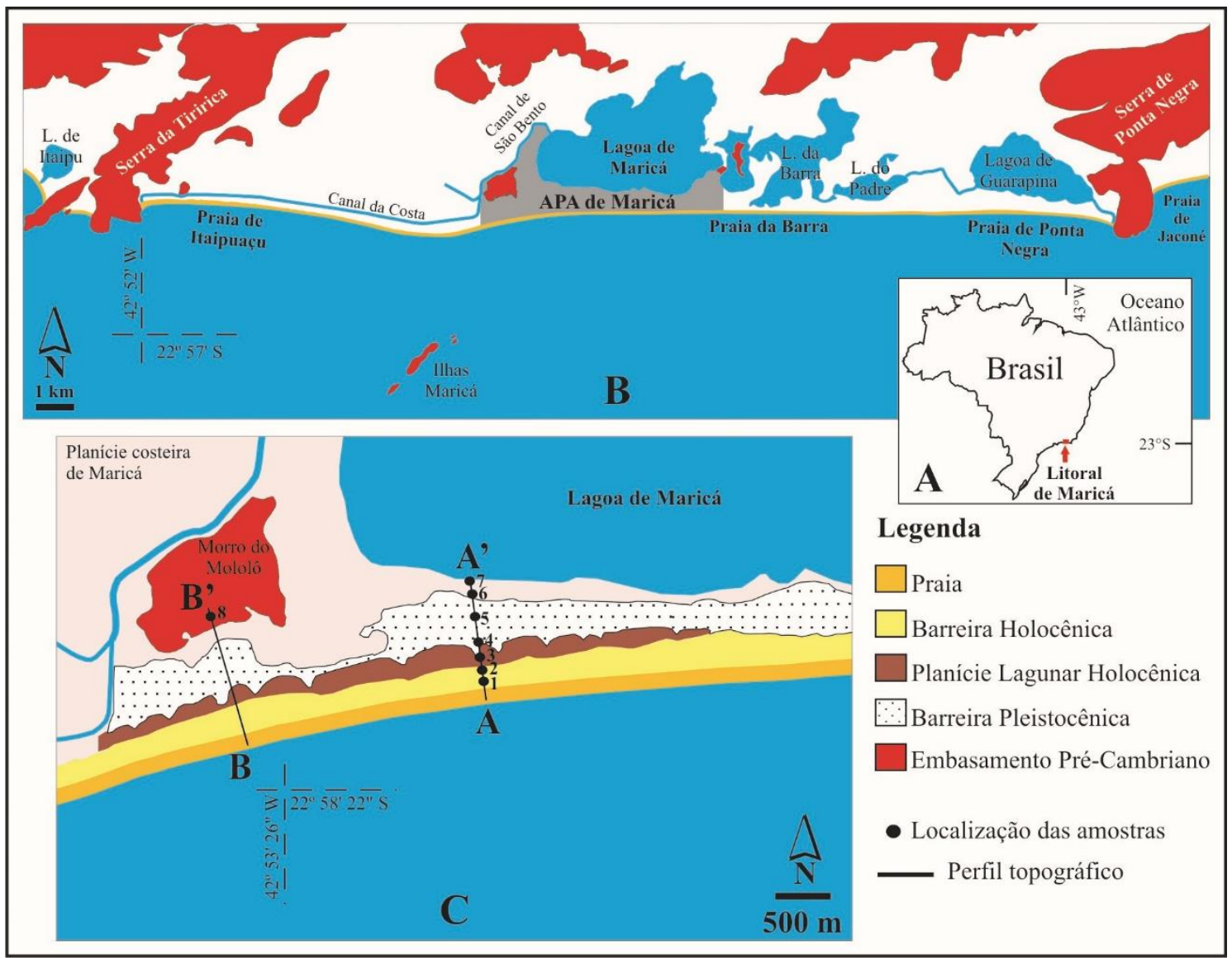

Figura 1: (A, B) Localização da área de estudo e (C) dos pontos de identificação das comunidades vegetais estudadas na APA de Maricá. Geomorfologia e sistemas deposicionais baseados em Silva et al.

(2014a, 2014b).

Os ambientes de restinga, do ponto de vista geral, são marcados pela sua condição costeira, pelo alto dinamismo e, ao mesmo tempo, por ser objeto de muitos estudos científicos. No Brasil, foi objeto de intensa ocupação urbana, portuária e industrial. Desta forma, os trechos remanescentes são preciosidades para o meio 
ambiente, as comunidades tradicionais e a academia. Vários setores das ciências naturais e sociais se debruçam há décadas sobre tal formação como: Geologia, Geomorfologia, Botânica, Zoologia, Limnologia, Antropologia, Urbanismo, Geografia, entre outras. Assim, cada campo do conhecimento atribui ao termo restinga uma determinada concepção, ressaltando as especialidades de acordo com o objetivo e o recorte temático.

A legislação brasileira apresenta definições qualificadas sobre o ambiente em questão: a Resolução CONAMA nº 303 de 2002 e o Código Florestal - Lei no 12.651 de 2012 definem restinga com uma articulação importante entre os componentes geológicos-geomorfológicos e botânicos: “depósito arenoso paralelo à linha da costa, de forma geralmente alongada, produzido por processos de sedimentação, onde se encontram diferentes comunidades que recebem influência marinha, com cobertura vegetal em mosaico, encontrada em praias, cordões arenosos, dunas e depressões, apresentando, de acordo com o estágio sucessional, estrato herbáceo, arbustivo e arbóreo, este último mais interiorizado". Assim, encontramos na base legislativa nacional definições com elos entre os componentes geológico-geomorfológicos e biológicos. Considerar-se-á, diante do exposto, restinga como um ecossistema do Bioma Mata Atlântica, um sistema integrado e autofuncionante que consiste em interações dos elementos bióticos e abióticos, e cujas dimensões podem variar consideravelmente.

No Decreto Estadual n 41.612 de 2008 a mesma articulação aparece e destaque é atribuído aos aspectos geológico-geomorfológicos: "Ficam as restingas do Estado do Rio de Janeiro definidas como: planícies arenosas costeiras de origem marinha, abrangendo praias, cordões arenosos, dunas, depressões entrecordões e depressões entredunas com respectivos brejos, charcos, alagados e lagoas, cuja vegetação e fauna estão adaptadas às condições ambientais locais".

Especificamente sobre Vegetação de Restinga, a Resolução CONAMA no 417 de 2009 apresenta uma conceituação bastante abrangente, pois, além da conexão entre diferentes elementos, bióticos e abióticos, insere a formação vegetal em questão no seu conjunto, isto é, no ecossistema: "Vegetação de Restinga: o conjunto de comunidades vegetais, distribuídas em mosaico, associado aos depósitos arenosos costeiros quaternários e aos ambientes rochosos litorâneos - também considerados comunidades edáficas - por dependerem mais da natureza do solo do que do clima, encontradas nos ambientes de praias, cordões arenosos, dunas, depressões e transições para ambientes adjacentes, podendo apresentar, de acordo com a fitofisionomia predominante, estrato herbáceo, arbustivo e arbóreo, este último mais interiorizado ecossistema".

Foi aqui adotada a definição que articula os diferentes elementos que compõem tal ambiente na direção de considerá-lo um ecossistema, logo a partir da sua gênese, dinâmica e ligações entre os componentes. Sua formação é caracterizada pela diversidade, com a presença de vários microambientes construídos pelas diferenças no modelado, no substrato, na umidade, dos ventos, das ondas, do spray marinho, etc. Diante disto, a formação restinga só pode ser considerada enquanto um ecossistema, dentro da sua totalidade, sua complexidade e do seu conjunto. Assim, a presente investigação faz a opção em trabalhar como instrumental analítico com o conceito de vegetação de restinga enquanto um ecossistema costeiro, componente do Bioma Mata Atlântica, constituído em mosaicos.

A diversidade desse tipo de vegetação, que é subdividida em diferentes comunidades vegetais, está relacionada à variação e influência de diferentes fatores, como: insolação, vento, intrusão salina, ondas de tempestade e spray marinho, escassez de nutrientes e de água no solo (CORTE, 2009). Araújo e Henriques (1984) identificaram as seguintes comunidades vegetais que podem compor uma restinga: a) 
halófilas, vegetação situada na parte superior da praia e adaptada às condições de salinidade e à influência decorrente das variações de maré; b) psamófilas reptantes, vegetação adaptada a solos arenosos e onde predominam espécies herbáceas reptantes; c) slack, comunidade a sotavento das dunas móveis; sem muitas informações botânicas; d) thicket, vegetação arbustiva fechada, situa-se sobre as barreiras arenosas, nos pontos aonde as ondas não chegam, mesmo em períodos de fortes ressacas, subdivide-se em thicket de pós-praia e thicket de Myrtaceae; e) scrub, vegetação arbustiva aberta com formação de moitas em que os indivíduos não se tocam uns aos outros, pode-se encontrar três tipos de scrub: de Clusiaceae, de Arecaceae e de Ericaceae; f) brejo herbáceo, locais de topografia mais baixa situados entre as barreiras arenosas ou, algumas vezes, às margens das lagoas, apresentam-se úmidos a alagados, por acúmulo de água das chuvas, por afloramento do lençol freático, ou por serem antigos leitos de lagunas colmatadas, onde a água costuma ser salobra, abrange espécies herbáceas a herbáceas-arbustivas; g) floresta periodicamente inundada, encontrada nas depressões úmidas delimitando as barreiras arenosas, apresenta vegetação arbórea entre 10 a $15 \mathrm{~m}$ de altura; h) floresta permanentemente inundada, situada na borda das lagoas ou em áreas deprimidas e úmidas, apresenta uma vegetação com porte arbóreo entre 6 e $8 \mathrm{~m}$ de altura; i) floresta seca, comunidades florestais que podem ou não sofrer inundações durante o ano, apresenta vegetação arbórea com porte em torno de $10 \mathrm{~m}$ de altura (ARAÚJO e HENRIQUES, 1984).

\section{ÁREA DE ESTUDO}

A área estudada está localizada no município de Maricá, Estado do Rio de Janeiro, correspondendo à parte central da planície costeira, a "Restinga de Maricá", inserida na Área de Proteção Ambiental (APA). Situa-se a cerca de $20 \mathrm{~km}$ da entrada da Baía de Guanabara, entre as coordenadas $22^{\circ} 52^{\prime}$ a $22^{\circ} 54^{\prime} \mathrm{S}$ e $42^{\circ} 48^{\prime}$ a $42^{\circ} 54^{\prime}$ W (Figura 1). A planície costeira em questão é formada por diversos ambientes (praias, dunas, barreiras, lagoas, etc.) (Figura 2), com sedimentação predominantemente arenosa e com variações topográficas em torno de 9 metros em relação ao nível médio do mar (Silva et al., 2014b), responsáveis por diferenças de profundidade do nível freático ao longo do litoral. Essas formações arenosas encontram-se cobertas por vegetação de restinga, com presença de cactos, bromélias e espécies de diversas gramíneas e arbustos de baixo porte.

A área de estudo possui cerca de 8 quilômetros de extensão e uma área total de 844,16 ha. Foi transformada em Unidade de Conservação, juntamente com a Ilha Cardosa e a Ponta do Fundão, pelo Decreto no 7.230 de 23 de janeiro de 1984, mas seus zoneamentos governamentais só foram aprovados após 23 anos; são eles o Plano de Manejo - Decreto Estadual no 41048/2007 e o Plano Diretor Setorial - Lei Municipal 2331/2010, ambos questionados na Justiça Estadual e Federal. Esse trecho do litoral de Maricá apresenta uma biodiversidade considerável, com cerca de 408 espécies de flora e fauna, sendo várias raras e endêmicas (GUERRA et al., 2010), como Dyckia pseudococcinea L.B.Sm. (Bromeliaceae), endêmica de Maricá e criticamente em perigo; Schaueria calycotricha (Link e Otto) Nees (Acanthaceae) e Neoregelia compacta (Mez) L.B.Sm. (Bromeliaceae), endêmicas do Rio de Janeiro; e Cattleya harrisoniana Batem. ex Lindl. (Orchidaceae), além de sítios arqueológicos e alguns recursos minerais (FARIA e BOHRER, 2005; LOUREIRO et al., 2010). No entanto, a APA de Maricá apresenta diversos problemas decorrentes do abandono, do acúmulo de lixo e queimadas, da mineração ilegal de areias e tráfego irregular de veículos sobre as dunas (SILVA et al., 2014c) (Figura 3), com várias espécies ameaçadas de extinção (Tabela 
1). Apesar dos problemas apontados, a faixa costeira em estudo, embora bastante utilizada para diversos fins no decorrer do tempo, ainda mantém vegetação nativa e alta biodiversidade, o que a torna de grande relevância para o desenvolvimento de estudos dessa natureza.

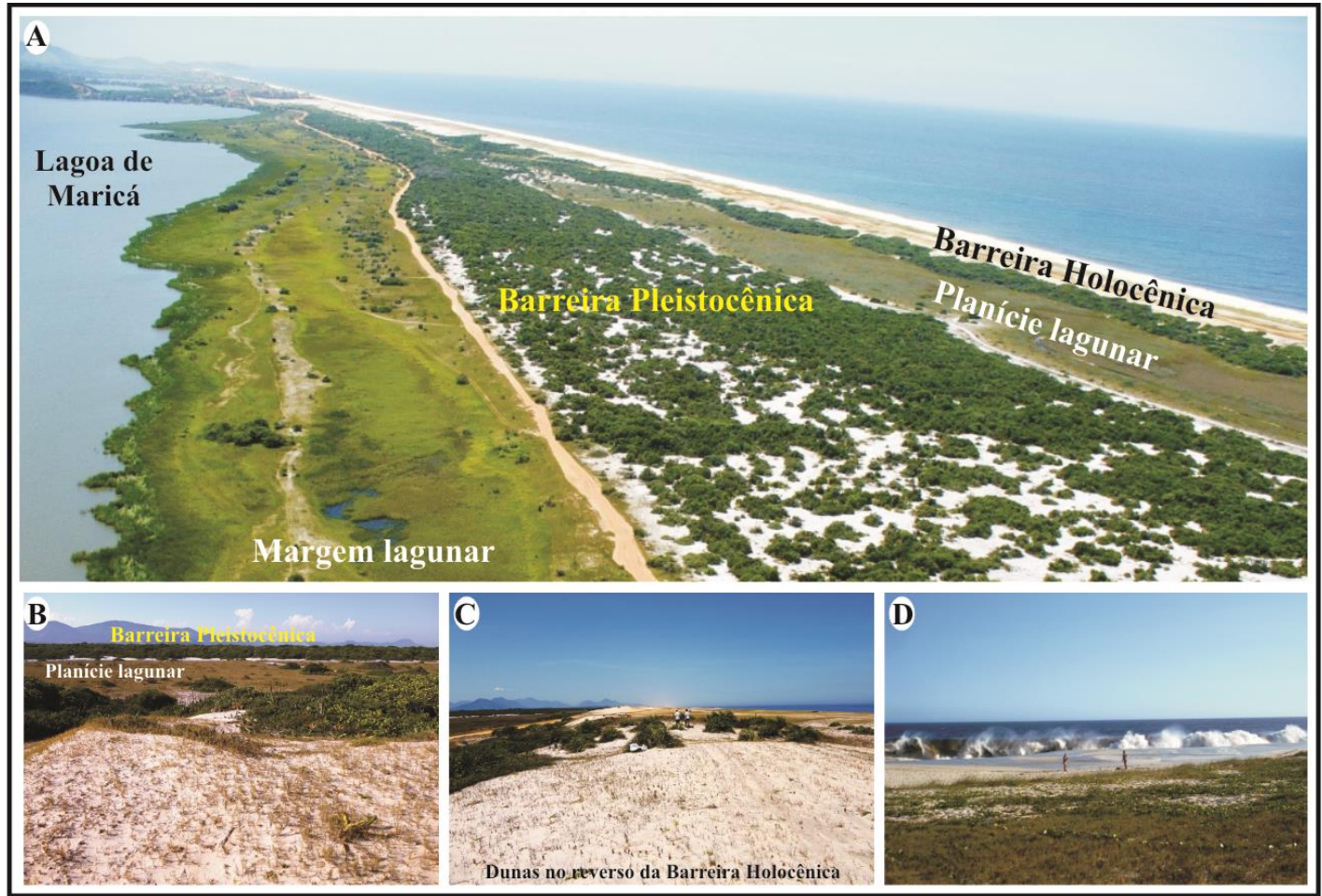

Figura 2: (A) Planície Costeira de Maricá, (B, C, D) com uma geomorfologia típica de barreiras arenosas associadas a sistemas lagunares. Fotos: A - Desirée Guichard (2009); B, C, D - André Silva (2009).

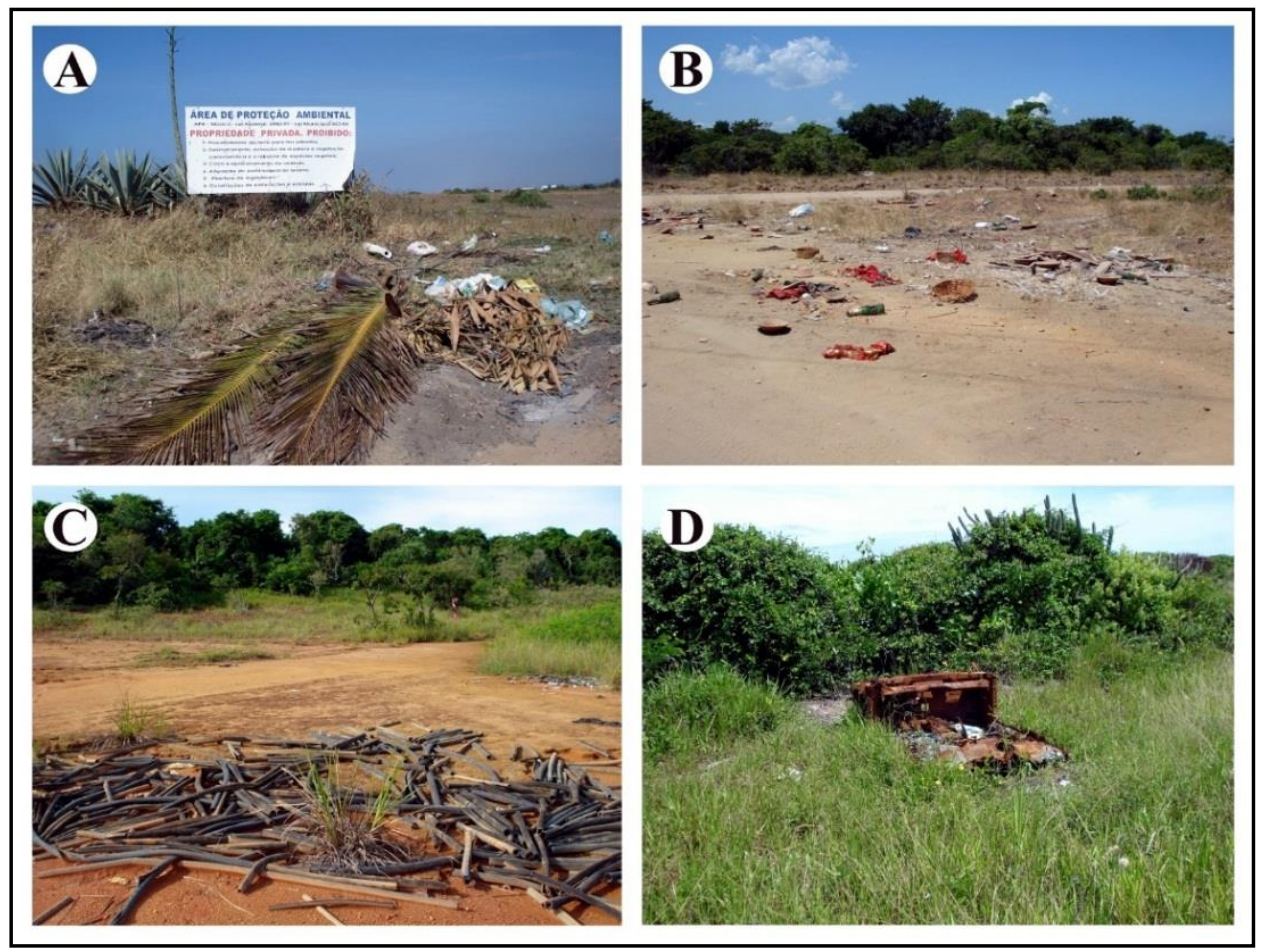

Figura 3: Descarte irregular de lixo (A, B, C) e carcaça de automóvel em meio a vegetação de restinga (D). Fotos: André Silva (2010). 
Tabela 1 - Lista de espécies ameaçadas da Restinga de Maricá

(Fonte: Barros et al., 2009).

\begin{tabular}{llc}
\hline & Nome científico & Grau de ameaça \\
\hline APOCYNACEAE & Ditassa maricaensis Fontella \& E. A. Schwars & EN \\
ARECACEAE & Allagoptera arenaria (Gomes) Kuntze & VU \\
BROMELIACEAE & Aechmea nudicaulis (L.) Griseb. & VU \\
& Dyckia pseudococcinea L. B. Sm. & CR \\
& Edmundoa lindenii (Regel) Leme & EN \\
& Neoregelia compacta (Mez) L. B. Sm. & EN \\
& Neoregelia cruenta (Graham) L. B. Sm. & VU \\
& Tillandsia mallemontii Glaz. ex Mez & EN \\
& Tillandsia tenuifolia L. & VU \\
& Tillandsia usneoides (L.) L. & VU \\
CACTACEAE & Vriesea neoglutinosa Mez & VU \\
& Melocactus violaceus Pfeiff. & VU \\
MALVACEAE & Rhipsalis maricensis Scheinvar & VU \\
RUBIACEAE & Pavonia alnifolia A. St.-Hil. & VU \\
SAPOTACEAE & Melanopsidium nigrum Cels & VU \\
\hline CR & Pouteria psammophila (Mart.) Radlk. & EN \\
\hline
\end{tabular}

$\mathrm{CR}$ - criticamente ameaçada $\mathrm{VU}$ - vulnerável $\quad \mathrm{EM}$ - em perigo

A planície costeira de Maricá exibe uma geomorfologia caracterizada pela presença de duas barreiras arenosas separadas por pequenas lagunas colmatadas e pelas Lagoas de Maricá, Barra, Padre e Guarapina (Figuras 1 e 2). A barreira arenosa interna (Figura 2A e B) e, consequentemente, mais antiga, foi formada no Pleistoceno (SILVA et al., 2014a). Esta barreira está localizada a cerca de 300 metros da primeira e possui 7 a 9 metros de altura em relação ao nível médio do mar (SILVA et al., 2014b). A barreira arenosa externa localizada mais próxima do mar (Figura 2A e C) possui uma altura de cerca de 7 metros em relação ao nível médio do mar (SILVA et al., 2014b). Essa barreira formou-se durante a última transgressão marinha ocorrida no Holoceno, possibilitando a formação de pequenas lagoas à sua retaguarda (IRELAND, 1987; PEREIRA et al., 2003; SILVA et al., 2014a). As comunidades vegetais que recobrem essas formações arenosas desenvolveram-se em diferentes contextos geocronológicos, considerando-se as diferenças de idades entre os sistemas barreira-laguna. O desenvolvimento da cobertura vegetal ao longo da planície costeira de Maricá foi influenciado por fases de transgressão e regressão marinha desde o Pleistoceno Tardio, cuja idade do sistema barreira-laguna interno corresponde a 50.000 anos AP aproximadamente, conforme Silva et al. (2014a).

O litoral de Maricá apresenta uma intensa dinâmica devido à exposição direta à incidência de ondas de tempestades (Figura 2D), que causam grandes variações morfológicas na praia e, eventualmente, problemas nas áreas com construções localizadas próximas a ela (LINS-DE-BARROS, 2005; SILVA et al., 2008, 2014b). As variações diárias no nível do mar em resposta às oscilações de maré não ultrapassam 1,5 metro (DHN, 1979).

O clima da região de Maricá foi classificado como tropical quente, superúmido, com estação subseca (NIMER, 1989). Dados meteorológicos de Niterói, município vizinho a Maricá, registram uma temperatura média anual de $23,2^{\circ} \mathrm{C}$, sendo a média das máximas do mês mais quente (fevereiro) $32,2^{\circ} \mathrm{C}$ e das mínimas do mês mais frio (julho) $15,1^{\circ} \mathrm{C}$. A precipitação média anual é de $1.230,8 \mathrm{~mm}$, com $69,2 \%$ ocorrendo entre novembro e abril (Departamento Nacional de Meteorologia, período de 1931 a 1968).

A flora presente na restinga no Município de Maricá é bem diversificada, como ressaltado por Oliveira e Silva (1989). Esses autores identificaram 379 espécies em 268 
gêneros distribuídos em 84 famílias botânicas, sendo as mais representativas: Fabaceae (29 sp.), Asteraceae (22 sp.), Euphorbiaceae (21 sp.), Orchidaceae (16 sp.), Bromeliaceae (15 sp.), Rubiaceae (15 sp.), Myrtaceae (14 sp.) e Cactaceae (13 sp.). Representantes de algumas famílias como Anacardiaceae, Cactaceae, Arecaceae, Malpighiaceae, Clusiaceae, também se destacam na paisagem litorânea. Qualitativamente, algumas espécies são expressivas do ponto de vista biológico, seja como alimento para a fauna ou para a própria comunidade vegetal.

\section{MATERIAIS E MÉTODOS}

Este trabalho foi realizado a partir de um levantamento bibliográfico sobre comunidades vegetais de restingas e, mais especificamente, sobre a Restinga de Maricá. Para esta pesquisa, foi adotada a classificação de Araújo e Henriques (1984), apresentada acima, com as adaptações necessárias para a planície costeira de Maricá.

Foram utilizados dados de topografia obtidos por Silva (2011), objetivando a caracterização morfológica dos ambientes (barreiras e lagoas) e subambientes (praias, dunas, margem lagunar) da planície costeira de Maricá. A partir dos dados préexistentes e de imagens de satélite disponibilizadas através do Google Earth foi feito o reconhecimento do local e a seleção dos pontos para a realização dos trabalhos de campo para identificação das comunidades vegetais da Restinga de Maricá. Cinco trabalhos de campo foram realizados (17 de abril de 2011, 2 de maio de 2011, 5 de agosto de 2011, 6 de julho de 2012 e 23 de novembro de 2012), o que permitiu o acompanhamento do período de floração e frutificação das espécies em todas as estações do ano, o que foi fundamental para a correta identificação das espécies. A identificação das espécies em campo foi devidamente catalogada e acompanhada de registro fotográfico. Espécies com identificação duvidosa foram coletadas e herborizadas, seguindo técnicas comumente empregadas em taxonomia vegetal (FIDALGO e BONONI, 1989), seguida de posterior identificação através de bibliografia especializada, consulta a especialistas e comparações com espécimes em herbários. Para a descrição das comunidades vegetais foram selecionadas as espécies com grande número de indivíduos ou de maior representatividade na paisagem. Consideraram-se também as variáveis relacionadas às condições ambientais presentes em cada uma, tais como: topografia, distância em relação ao mar e alcance do spray marinho, tipo de substrato, condições hidrológicas, ambiente de formação, etc.

\section{RESULTADOS E DISCUSSÃO}

A restinga de Maricá abriga várias espécies da flora ameaçadas de extinção e endêmicas: (GUERRA et al., 2010), como Dyckia pseudococcinea L.B.Sm. (Bromeliaceae), endêmica de Maricá e criticamente em perigo; Schaueria calycotricha (Link e Otto) Nees (Acanthaceae) e Neoregelia compacta (Mez) L.B.Sm. (Bromeliaceae), endêmicas do Rio de Janeiro; e Cattleya harrisoniana Batem. ex Lindl. (Orchidaceae), também ameaçada de extinção.

A morfologia variada ao longo da Restinga de Maricá promove a criação de vários microambientes facilitando o desenvolvimento de diversas formações vegetais que caracterizam este complexo ecossistema, apresentando perfis de vegetação no sentido mar-interior (OLIVEIRA e SILVA, 1989). Essas comunidades vegetais apresentam um padrão de distribuição perpendicular à linha de costa, fortemente influenciado pela variabilidade topográfica dos diversos ambientes geomorfológicos (praia, barreiras, dunas, planície lagunar, etc.), pelo alcance do spray marinho e da cunha salina, pela proximidade em relação ao lençol freático (que chega a aflorar na 
área da planície lagunar) e por condições edáficas (Figura 4).

Com base na classificação de Araújo e Henriques (1984), foram encontradas as seguintes comunidades vegetais: Halófila-psamófila, Scrub, Brejo herbáceo, Slack, e Floresta seca. Além dessas, foi identificada outra comunidade, que recebeu a denominação de Vegetação arbustiva, presente nas margens da lagoa (Figuras 4 e 5).

1) HALÓFILA-PSAMÓFILA: adaptada a um substrato arenoso, sob condições de salinidade e influência das oscilações de marés. Nesta comunidade predominam espécies herbáceas reptantes, como Ipomoea pes-caprae (L.) R.Br., Alternanthera littoralis var. maritima (Mart.) Pedersen, Remirea maritima Aubl., além de Panicum sp. (Figuras 4, 5a e 5b). Oliveira e Silva (1989) também identificaram nessa comunidade Blutaparon portulacoides (A.St.-Hil.) Mears, Sporobolus virginicus (L.) Kunth e Ipomoea littoralis (L.) Boiss. A comunidade halófila, em certas épocas do ano, é afetada pela maior incidência de ondas de tempestades, que promovem a diminuição da faixa de areia da praia e, consequentemente, o espaço físico das psamófilas fica reduzido, recompondo-se posteriormente. A área ocupada por esta comunidade no pós-praia, por vezes modifica-se pela ação dos ventos, justapondo-se à localizada na retaguarda da barreira ou ocupando a crista das dunas. Na área do pós-praia destacam-se: Sophora tomentosa L., Eugenia uniflora L., Schinus terebinthifolius Raddi e Cereus fernambucensis Lem., que ocorrem com porte bastante reduzido, sendo que a primeira é mais raramente observada em direção ao interior desta área (OLIVEIRA e SILVA, 1989).

2 e 5) SCRUB: vegetação aberta com formação de moitas, onde predominam as espécies arbustivas Clusia fluminensis Planch. \& Triana, Byrsonima sericea DC. e Humiria balsamifera (Aubl.) J.St.-Hil. e a bromeliácea Neoregelia cruenta (R.Graham) L.B.Sm., pioneira no processo de formação das moitas. São encontrados dois scrubs, um sobre a Barreira Holocênica (Figuras 4, 5c e 5d), onde predomina a vegetação arbórea, com altura média de 4 a $8 \mathrm{~m}$, sob a qual se desenvolvem numerosas epífitas; e outro sobre a Barreira Pleistocênica (Figuras 4, 5e e 5f), em geral abrigado pelas dunas, apresentando uma vegetação densa em alguns trechos formados por um emaranhado de difícil penetração. Assim como na Barreira Holocênica, aí predomina a vegetação arbórea, também com altura média de 4 a $8 \mathrm{~m}$, onde, além das espécies já citadas, são encontradas Eugenia uniflora L., Schinus terebinthifolius Raddi e Clusia lanceolata Cambess., sob a qual se desenvolvem numerosas epífitas, como a Tillandsia stricta Sol., além de espécies não arbóreas como Cereus fernambucensis Lem., Allogoptera arenaria (Gomes) Kuntze e Neoregelia cruenta (R.Graham) L.B.Sm. (OLIVEIRA e SILVA, 1989). Entre as barreiras predomina a "restinga aberta", onde se destacam as Bromeliaceae, particularmente Neoregelia cruenta (R.Graham) L.B.Sm. e Vriesea neoglutinosa Mez, contornando as áreas próximas às moitas, e Tillandsia stricta Sol, como epífita (OLIVEIRA e SILVA, 1989).

3 e 6) BREJO HERBÁCEO: dois brejos foram encontrados na área de estudo, um localizado na depressão topográfica entre as duas barreiras arenosas, com predomínio das famílias Poaceae e Cyperaceae, além de Sagittaria lancifolia L. e a pterifófita Blechnum sp. (Figuras 4, 5g e 5h); outro próximo à lagoa de Maricá, onde também predominam espécies de Poaceae e Cyperaceae, além de Typha domingensis Pers., Marcetia taxifolia (A.St.-Hil.) DC. e Ludwigia octovalvis (Jacq.) P.H.Raven (Figuras 4, $5 \mathrm{i}$ e $5 \mathrm{j}$ ). $\mathrm{O}$ brejo herbáceo aparece limitado por bolsões de umidade, com dimensões variáveis entre 2 e $10 \mathrm{~m}$ de diâmetro, mantendo sua fase mais vigorosa em períodos chuvosos, quando o lençol freático se encontra mais elevado. Durante o ano, pode ocorrer uma sucessão de espécies de curta duração, inclusive com a presença de liquens 
(em especial Cladonia sp.). Periodicamente, o solo fica quase desnudo, com vestígios de uma vegetação que se renova por meio de estolões e rizomas (OLIVEIRA e SILVA, 1989).

4) $\boldsymbol{S L A C K}$ : essa comunidade de plantas aparece em um trecho estreito (cerca de 30 a 50 metros), localizado entre a planície lagunar e a Barreira Pleistocênica, com vegetação reptante e ervas anuais composto por Cuphea flava Spreng., Stachytarpheta sp., além de gramíneas (Figuras 4, 5k e 51).

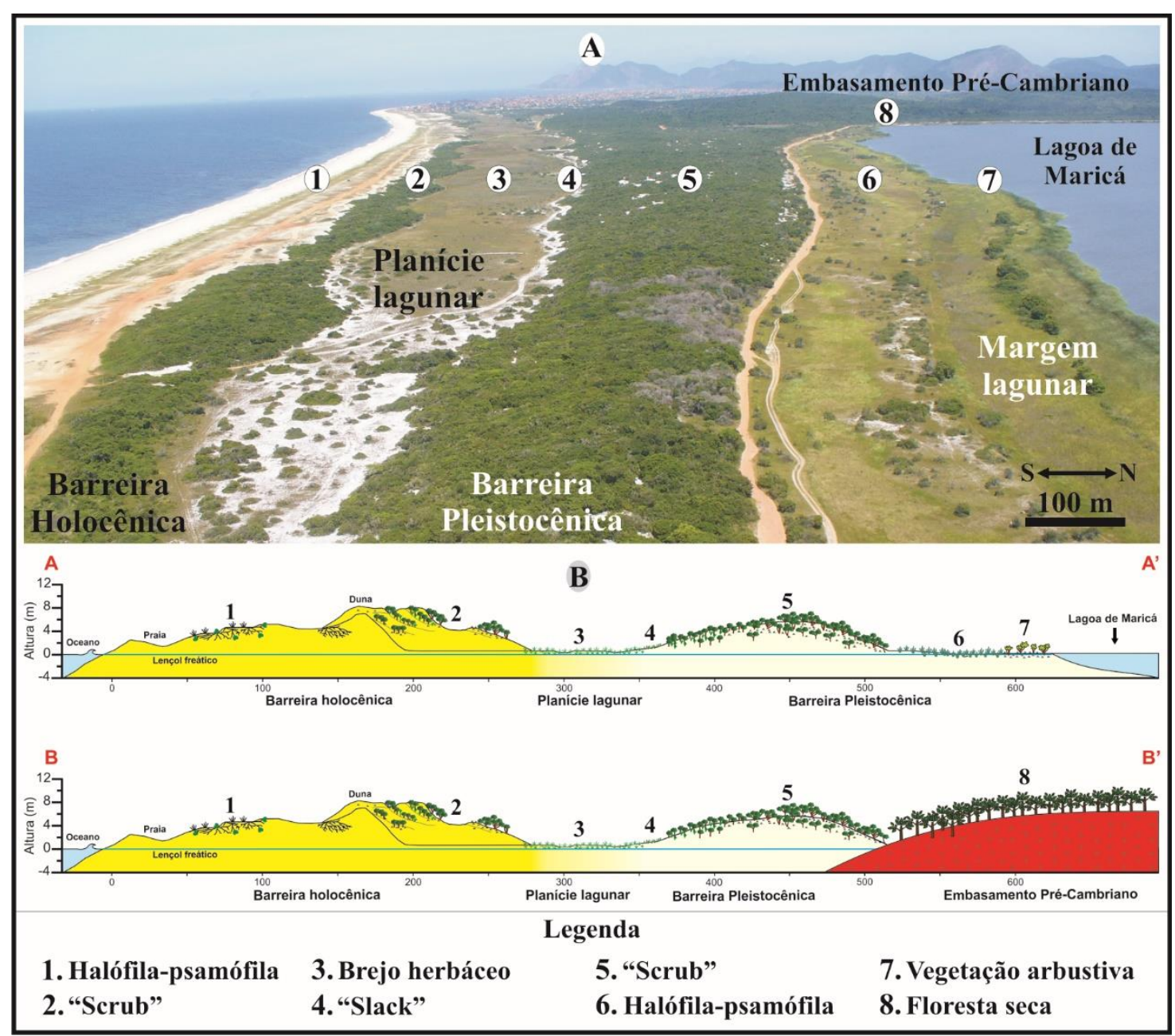

Figura 4: Distribuição das comunidades vegetais da APA de Maricá ao longo dos ambientes que compõem a planície costeira: (1) Halófila-psamófila, na praia; (2) Scrub sobre a Barreira Holocênica; (3) Brejo herbáceo, na planície lagunar; (4) Slack, na porção frontal da Barreira Pleistocênica; (5) Scrub, na crista da Barreira Pleistocênica; (6) Brejo herbáceo, na margem lagunar próxima à Lagoa de Maricá; (7) Vegetação arbustiva nas margens da Lagoa de Maricá; (8) Floresta seca, sobre o embasamento alterado.

Foto A: Desirée Guichard (2009). Figura B modificada de Borrelli et al. (2014); Geomorfologia e sistemas deposicionais baseados em Silva et al. (2014a e 2014b). 


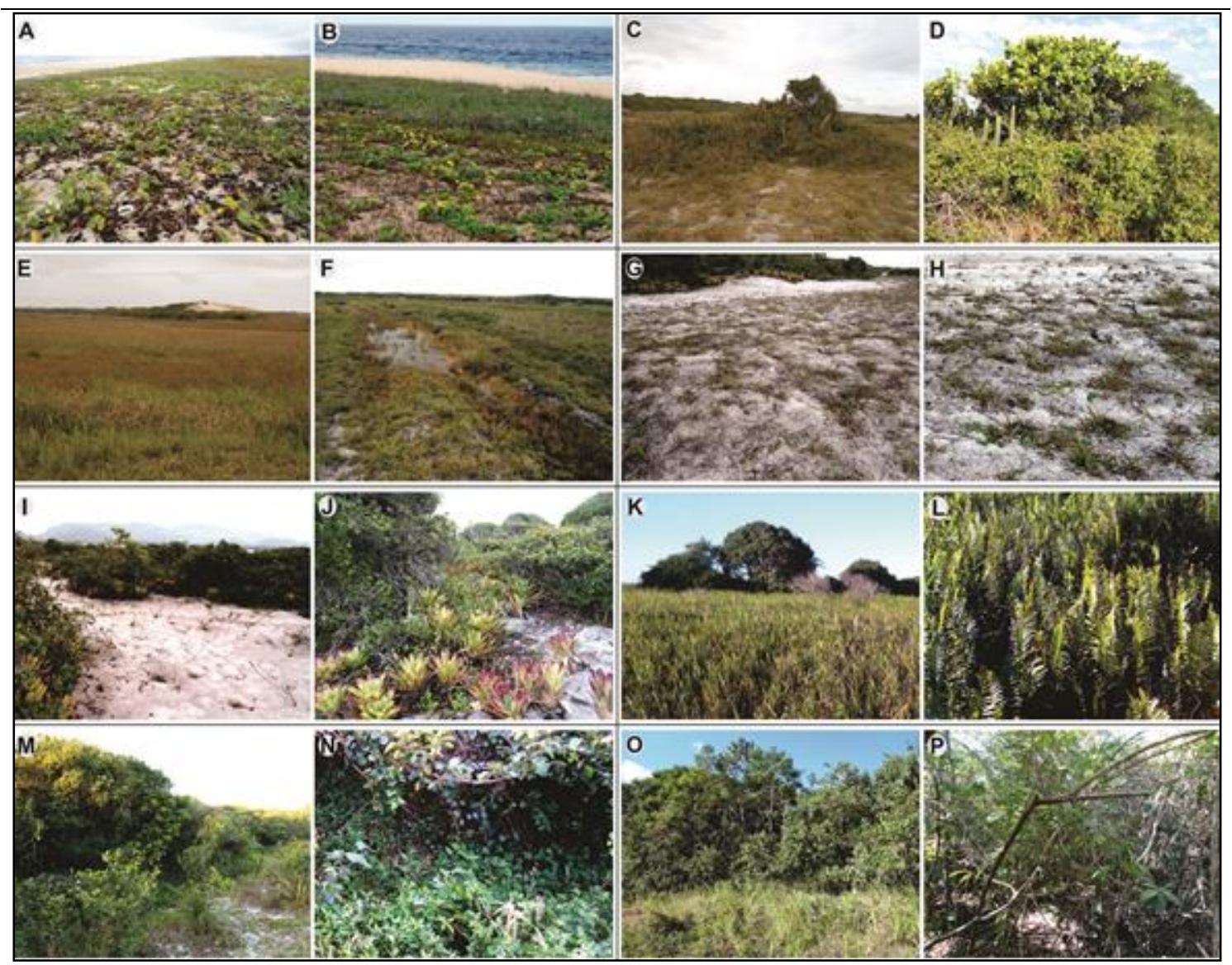

Figura 5: Visão geral e em detalhe das comunidades vegetais da Restinga de Maricá: (A, B) Halófilapsamófila; (C, D) Scrub sobre a Barreira Holocênica; (E, F) Scrub sobre a Barreira Pleistocênica; (G, H) Brejo herbáceo na planície lagunar; (I, J) Brejo herbáceo próximo à Lagoa de Maricá; (K, L) Slack; (M,

$\mathrm{N})$ Vegetação arbustiva às margens da Lagoa de Maricá; $(\mathrm{O}, \mathrm{P})$ Floresta seca.

7) VEGETAÇÃO ARBUSTIVA NAS MARGENS DA LAGOA DE MARICÁ: com cerca de 4 metros de altura, formando uma linha contínua ao redor da margem da lagoa na APA de Maricá, é a área mais antropizada, com maior ocorrência de espécies invasoras como Sansevieria trifasciata Prain e Euphorbia tirucalli L. Entre as dominantes destacam-se: Dalbergia ecastophyllum (L.) Taub., Varronia curassavica Jacq., Schinus terebinthifolius Raddi e Hydrocotyle bonariensis Lam. (Figuras 4, 5m e 5n). Nas áreas adjacentes externas à APA de Maricá esta comunidade vegetal não aparece com a mesma exuberância devido ao elevado grau de alteração resultante das construções e modificações introduzidas neste ambiente.

8) FLORESTA SECA: com estrutura arbórea bem desenvolvida, ocupa boa parte das áreas correspondentes ao embasamento alterado de idade Pré-Cambriana, representada pelo Morro do Mololô na sua quase totalidade. Essa comunidade não apresenta espécies dominantes. Porém, no sub-bosque encontram-se grandes populações de Calathea sp., Bromelia antiacantha Bertol. e Astrocaryum aculeatissimum (Schott) Burret (Figuras 4, 5 o e $5 \mathrm{p})$.

Os ecossistemas em questão estão ameaçados de destruição e descaracterização, pois está em curso na localidade à implantação do mega-empreendimento denominado Complexo Turístico-Residencial Fazenda de São Bento da Lagoa, do grupo empresarial luso-espanhol IDB-Brasil. A restinga de Maricá está inserida em uma propriedade privada, a Fazenda São Bento da Lagoa, e em Terras da União (Terrenos de Marinha, 
Acrescidos de Marinha e praias), num total de 844,16 hectares. O Decreto Estadual $\mathrm{n}^{\mathrm{o}}$ 7230/1984 não permitia o parcelamento de terras, fato que impediu a implantação de Planos Diretores ou Planos de Manejo, com respectivos zoneamentos, que dessem anuência para qualquer tipo de uso urbano. Tal norma garantiu por um bom tempo a proibição de implantação de loteamentos e condomínios na restinga e em toda a Faixa Marginal de Proteção do Sistema lagunar de Maricá, possibilitando a preservação dos diversos ecossistemas associados à restinga.

No ano de 2007, dois meses após a apresentação do empreendimento na Feira Imobiliária de Madrid, com a presença de gestores estaduais e municipais, a Comissão Estadual do Controle Ambiental CECA da Secretaria Estadual do Ambiente do Rio de Janeiro aprovou a primeira versão do zoneamento da APA de Maricá. Após ajustes, no mesmo ano, o governador aprovou o Plano de Manejo da APA de Maricá no Decreto $\mathrm{n}^{\mathrm{o}}$ 41048/2007. Este documento anulou o artigo que proibia o parcelamento de terras do Decreto de criação da APA e liberou para uso urbano, verticalizado inclusive, $50 \%$ da restinga e $80 \%$ do território da comunidade pesqueira de Zacarias.

A sociedade civil organizada de Maricá, que não foi consultada pelo órgão ambiental para a elaboração do zoneamento e aprovação pela CECA-SEA, ingressou com pedidos de ação nos Ministérios Públicos Estadual e Federal em 2008 contra o Decreto. No total, vinte e seis instituições civis participaram desta investida (FREIRE, 2013). A Associação de Proteção das Lagunas de Maricá - APALMA e a Associação de Cultura e Lazer dos Pescadores de Zacarias - ACCLAPEZ entraram em 2009 com uma ação na justiça pela anulação da mesma norma e com uma liminar que impede qualquer empreendimento na APA. Assim, o conflito territorial que já existia desde os anos de 1950 emerge novamente e retoma a intensa batalha judicial. Em 2010 o Grupo de Apoio Técnico do Ministério Público Estadual elabora um relatório detalhado e conclui que o "Plano de Manejo da APA de Maricá é um instrumento de destruição da restinga" (Informação Técnica, 116/2010). A segunda instância da Justiça Estadual aprova a Liminar da ação APALMA - ACCLAPEZ em 2013 e dá início a uma longa disputa de sua anulação e restabelecimento. Pesquisadores das universidades públicas no estado do Rio de Janeiro (FFP-UERJ, UFRJ e UFF) conseguiram que suas instâncias superiores aprovassem moções oficiais de reprovação de qualquer investimento que descaracterize a comunidade tradicional de Zacarias e o ambiente nativo presente. Após ser derrubada e revigorada diversas vezes a Liminar se encontra, atualmente, em vigor. Outra se soma a ela, referente à Ação Judicial ingressada na Justiça Federal pelo Ministério Público Federal em 2016, de mesmo teor. Desta forma, a Licença Prévia do projeto da empresa IDB Brasil concedida pelo INEA, $n^{\circ}$ IN030651 de 21 de maio de 2015, foi anulada em 20 de dezembro de 2016. Trata-se de decisões provisórias, até as ações principais serem julgadas. Logo, o conflito permanece em curso.

Consta no EIA-RIMA, aprovado pelo órgão ambiental estadual, o desmatamento de 148,43 hectares de vegetação nativa do Ecossistema de Restinga, logo Bioma Mata Atlântica, protegido por legislações federal e estadual. Estão previstos 52 prédios, milhares de casa, dois shopping centers, dois campos de golfe, centros comerciais, clubes, hotéis, hípica de porte internacional e enormes superfícies destinadas à infraestrutura como estradas, centenas de ruas e calçadas, servidões, gramados, jardins e estacionamentos. $\mathrm{O}$ empreendimento possuía licença prévia com aval para destruir ecossistemas de restinga e floresta atlântica nativos, de alta biodiversidade, com mais de 400 tipos botânicos, 19 espécies endêmicas, várias espécies ameaçadas de extinção, locais de reprodução de aves, locais de pouso e invernada de aves migratórias nacionais e internacionais, dunas raras de areias grossas a médias, sítios históricos e arqueológicos. Inclui-se a possível mutilação do amplo Território da Comunidade 
pesqueira artesanal de Zacarias presente na localidade desde 1797, que realiza a genuína "pesca de galho" com recursos do ambiente supracitado. Trata-se da restinga com o maior número de trabalhos científicos do país, um campus vicinal das universidades brasileiras mais renomadas e, ainda, Área Núcleo I da Reserva da Biosfera da Mata Atlântica (UNESCO / ONU) (CNRBMA, 2003).

\section{CONSIDERAÇÕES FINAIS}

Este estudo possibilitou a caracterização de oito comunidades vegetais da Restinga de Maricá e as principais espécies vegetais que as constituem, assim como, as variáveis ambientais que atuam na distribuição geográfica destas. Essas comunidades estão distribuídas paralelamente ao litoral e no sentido sul-norte, em resposta: (1) a influência da topografia, que interfere no padrão de ventos locais e na profundidade do nível freático; (2) a salinidade, que diminui progressivamente em direção ao interior do continente, devido à menor influência da cunha salina e do alcance do spray marinho; (3) e em função das características edáficas (textura, teor de umidade e matéria orgânica no solo, etc.).

A Restinga de Maricá é uma das mais bem preservadas e estudadas do litoral fluminense, permitindo a identificação de comunidades vegetais com plantas nativas e inúmeras espécies endêmicas. No momento, este remanescente de restinga e o território da comunidade pesqueira de Zacarias se encontram ameaçados de destruição e descaracterização, pelos zoneamentos governamentais que aprovaram o uso urbano, verticalizado inclusive, em locais com a vegetação de restinga nativa e em estágio avançado de regeneração. O projeto imobiliário-turístico, que já obteve Licença Prévia do órgão ambiental estadual - o INEA (Instituto Estadual do Ambiente), prevê a supressão de 148 hectares de vegetação de ecossistema nativo, de acordo com o respectivo Estudo de Impacto Ambiental. Assim, este tipo de pesquisa é importante para tornar pública a diversidade e riqueza ambiental ali presente, contribuir para o aprofundamento do conhecimento sobre o litoral brasileiro e cooperar na preservação deste ecossistema fundamental para a faixa costeira brasileira e, por conseguinte, do Bioma Mata Atlântica.

\section{Agradecimentos}

Os autores gostariam de agradecer à Fundação de Amparo à Pesquisa do Estado do Rio de Janeiro - FAPERJ pela concessão do Auxílio à Pesquisa (Processo E26/111.722/2010) e da Bolsa de Iniciação Científica.

\section{REFERÊNCIAS}

ARAUJO, D. S. D., HENRIQUES, R. P. B. Análise florística das restingas do estado do Rio de Janeiro. In: LACERDA, L. D.; ARAUJO, D. S. D.; CERQUEIRA, R.; TURCQ, B. (eds.). Restingas: Origem, Estrutura e Processos. CEUFF, Niterói, p.47-60, 1984.

BARROS, A. A.; SANTOS, M. G.; PINTO, L. J. S.; F.; D. G.; HOLZER, W. Restinga de Maricá: Ecossistema, comunidade tradicional e Unidade de Conservação. São 
Gonçalo: Faculdade de Formação de Professores/Universidade do Estado do Rio de Janeiro, 2009.

BORRElli, N. L., COE, HELOISA H. G., SOUSA, L. O. F., SANTOS, C. P., RAMOS, Y. B. M., SILVA, A. L. C., SILVESTRE, C. P. Reference Collections of Plant Communities from "Restinga" of the Coastal Plain of Maricá, Rio de Janeiro, Brazil. In: Synthesis of Some Phytolith Studies in South America (Brazil and Argentina). 1 ed., Nova Science Publishers, New York, v.1, p. 29-47. 2014.

CNRBMA. Conselho Nacional da Reserva da Biosfera da Mata Atlântica. A Reserva da Biosfera da Mata Atlântica no do Estado do Rio de Janeiro. Caderno n 22. São Paulo, 2003.

CONSELHO NACIONAL DO MEIO AMBIENTE. Resolução 07 de 23 de julho de 1996 da CONAMA disponível em: http://licenciamento.cetesb.sp.gov.br/legislacao/federal/resolucoes/ 1996_Res_CONAMA_7.pdf. Acesso em 14/11/2012.

CONSELHO NACIONAL DO MEIO AMBIENTE. Resolução CONAMA n 303 de 20 de março de 2002. Disponível em: www.mma.gov.br/port/conama/res/res02/res30302.html. Acesso em 16/3/ 2014.

CORTE, J. Biomas de Restinga. Dez. Disponível em: http://www.pt.slideshare.net/ JadeCorte/bioma-restinga. 2009. Acesso em 5/11/2014.

FARIA, C. P., BOHRER, C. B. A. As Unidades de Paisagem da APA Estadual de Maricá/RJ. In: XI Simpósio Brasileiro de Geografia Física Aplicada, 2005. Anais. São Paulo, USP, p.2.947-2.953. 2005.

FIDALGO, O., BONONI, V. L. R. Técnica de coleta, preservação e herborização de material botânico. (Série Documentos) São Paulo. 62p. 1989.

FREIRE, D. G. Expansão Imobiliária e conflito ambiental, uma avaliação da disputa de uso na restinga de Maricá - RJ. Anais do XIII Simpósio Nacional de Geografia Urbana, 2013, Rio de Janeiro, UERJ, 2013.

INFORMAÇÃO TÉCNICA - 116/2010 Grupo de Apoio Técnico do Ministério Público do Estado do Rio de Janeiro. 2010. 
IRELAND, S. The Holocene sedimentary history of the coastal lagoons of Rio de Janeiro State, Brazil. In: Sea Level Changes. TOOLEY, M. \& SHENNAM, I. (eds.). Brazil Blackwell Ltd. Oxford pp. 25-66, 1987.

LINS-DE-BARROS, F. M. Risco e Vulnerabilidade à Erosão Costeira no Município de Maricá, Rio de Janeiro. Dissertação (Mestrado). PPGG / UFRJ. Rio de Janeiro, 147 p., 2005.

LOUREIRO, D. S.; MATIAS, M. L.; FREIRE, D. G. Avaliação do conflito sócioambiental na APA da restinga de Maricá-RJ. XVI Encontro Nacional dos Geógrafos. Porto Alegre, pp. 10, 2010.

NIMER, E. Climatologia do Brasil. 2 ed. IBGE. Rio de Janeiro. 1989.

OLIVEIRA, A. S.; SILVA, J. G. A Vegetação de Restinga no Município de Maricá- RJ (1). Acta Botânica Brasileira, 3(2): 1989, supl.

PEREIRA, A. J., GAMBÔA, L. A. P., SILVA, M. A. M., RODRIGUES, A. R., COSTA, A. A Utilização do Ground Penetraiting Radar (GPR) em Estudos de Estratigrafia na Praia de Itaipuaçú - Maricá (RJ). Revista Brasileira de Geofísica. EDUFF, Niterói, Vol 21 (2), p. 163-171, 2003.

SANTOS, M. G., BARROS, M. A., FREIRE, D. G, HOLZER, W. Valor científico da Restinga de Maricá. Manifesto dos pesquisadores. Rio de Janeiro, 2010.

SILVA, A. L. C. Arquitetura Sedimentar e Evolução Geológica da Planície Costeira Central de Maricá (RJ) ao longo do Quaternário. Tese (Doutorado). Geologia e Geofísica Marinha, Universidade Federal Fluminense, Niterói, 185 p., 2011.

SILVA, A. L. C., SILVA, M. A. M., SANTOS, C. L. Comportamento Morfológico e Sedimentar da Praia de Itaipuaçú (Maricá, RJ) nas últimas Três Décadas. Revista Brasileira de Geociências. Sociedade Brasileira de Geologia, 38 (1), p. 89-99, 2008.

SILVA A. L. C., SILVA M. A. M., GAMBOA L. A. P. \& RODRIGUES A. R. Sedimentary architecture and depositional evolution of the Quaternary coastal plain of Maricá, Rio de Janeiro, Brazil. Brazilian Journal of Geology, 44 (2): 191-206. 2014a. 
SILVA A. L. C., SILVA M. A. M., GRALATO J. C. A., SILVESTRE C.P. Caracterização geomorfológica e sedimentar da planície costeira de Maricá (Rio de Janeiro). Revista Brasileira de Geomorfologia, 15 (2): 231-249. 2014b. 